\title{
Combined PSO and IBF Algorithm for Short Term Hydro Thermal Scheduling
}

\author{
T.Balachander, P. Aruna Jeyanthy, D. Devaraj
}

\begin{abstract}
Hydro and thermal power plants are planned to reduce the overall operation cost of the thermal power plants by optimally allocating the hydro units and thermal units in the power generation system. In this research work a combined particle swarm optimization (PSO) and improved bacterial foraging algorithm (IBFA) is proposed for short term hydro thermal scheduling (STHTS) with prohibited operating zones (POZs). The PSO algorithm yields the fastest convergence rate and possesses maximum capability of finding the global optimal solutions to the HTS (Hydro Thermal Scheduling) problems. Also BFA has succeeded in solving several issues in optimization, but it demonstrates poor convergence characteristics for large-scale issues such as the STHTS problem. Critical improvements to the basic BFA are implemented to tackle this complex issue in view of its high-dimension search space. The chemotactic step is changed in IBF, so that the convergence becomes dynamic rather than static. The combined PSO-IBF algorithm is assessed on a typical power generation plants consists of a hydroelectric power plant and an equivalent thermal power plant with a time slot of six 12-hour intervals and simulated using the MATLAB software. The simulation result shows that the combined PSO-IBF algorithm yields minimum cost value and optimal convergence rate than the existing algorithms.
\end{abstract}

Keywords : Improved Bacterial Foraging Algorithm, Particle Swarm Optimization, Power Generation System, Short Term Hydrothermal Scheduling

\section{INTRODUCTION}

A modern power plant consists of numerous thermal power plant and hydro power plant that are coupled at numerous load centers via a power transmission network. Scheduling the hydro and thermal generation units is a significant work in the power generation systems. The major purpose of the HTS is to control the water release rate from every pool of the hydro unit at all stages so as to minimize the overall operating cost of the thermal power plants by fulfilling the load demands and various operational limits [1]. As there is no incremental cost for the hydro units, hydroelectric power generation is utilized at its maximum capacity so that the operating cost of thermal power plant is reduced.

Traditional approaches such as Gradient search (GS) [2],

Revised Manuscript Received on December 05, 2019.

T.Balachander, Research Scholar, Department of Electrical and Electronics Engineering, Kalasalingam Academy of Research and Education, Srivilliputtur, India, E mail: aimchandru68@gmail.com

Dr.P.Aruna Jeyanthy, Professor, Department of Electrical and Electronics Engineering, Kalasalingam Academy of Research and Education, Srivilliputtur, India, E mail: arunadarwin@yahoo.com

Dr.D.Devaraj, Senior Professor, Department of Electrical and Electronics Engineering, Kalasalingam Academy of Research and Education, Srivilliputtur, India, E mail: deva230@yahoo.com
Lagrange multiplier [3-5], and Dynamic programming (DP) [6-8] are available for solving the HTS problem by creating multiple assumptions to enhance the computational speed and effectiveness of the search process. These approaches provide favorable solution with less time while the cost equations are smooth. GS method is highly challenging to deal with the limitations on the power generation units. The pitfall of the Lagrange multiplier approach is the infeasible dual solution. The major disadvantage of DP method is the drastic increase in the computational load and memory requirements with the increase in the size of the power system.

Recently, artificial intelligence approach such as Neural network [15] and the evolutionary methods such as Simulated annealing (SA) [9-11], Genetic algorithm (GA) [12-14], , Evolutionary programming (EP) [16-19] and PSO algorithm [20-26] are developed to determine the best possible solution for HTS problem. The shortcomings of the SA algorithm are high difficulty to set the related regulation parameters and slow speed when used to a huge sized power generation system. Though the GA has the ability to quickly reach the highly effective area of the solution space, it faces more complications in precisely finding the optimal solution. EP technique is used to solve the extensive real-time problems and quicker than the GA. But, it is affected by various initial trial solutions. The meta-heuristic algorithms will provide a reasonable suboptimal solution within a short processing time, but they do not always assure the global optimal solution. Among them, PSO algorithm yields the maximum potential to find accurate global optimal solutions and convergence rate is obtained in short time. Also, this algorithm is inexpensive in terms of computing capacity and storage requirements [20]. The PSO-based heuristic optimization techniques provide the better solution [26].

This paper presents a combined PSO and IBF algorithm for STHTS. The PSO algorithm considers the volume of the water reservoir as a particle to avoid from the local minima. When the water discharge, hydro or thermal power generation is selected as a particle position the PSO algorithm converges in the similar region only. The PSO algorithm is highly effective in decreasing the cost while searching the complete search space than the existing meta-heuristic algorithms. By implementing PSO algorithm, total power generated by cascaded hydro power plant and thermal power plants with the POZs is optimally allocated in order to reduce the fuel cost of the thermal plant where as fulfilling various limitations on the power generation system. In the IBF algorithm, a decreasing dynamic function is applied for improving the convergence characteristics. PSO-IBF algorithm reliably and 
precisely follows a continually varying solution of the complex cost functions. It generates minimum cost outputs within a short time [27]. The combined PSO-IBF algorithm enables usage of the investigation and exploitation abilities of the search space and avoids wrong and premature convergence in many instances.

The whole manuscript is organized in the subsequent manner: Section II describes about the mathematical problem formulation including the equality and inequality limitations along with POZ limitations. Section III explains the research work including PSO algorithm and IBF algorithm. Section IV presents the simulation results of the PSO-IBF algorithm. Section $\mathrm{V}$ provides the conclusion of the proposed PSO-IBFA work.

\section{PROBLEM FORMULATION}

\section{Objective function}

The objective of the proposed work is to reduce the fuel cost of the thermal power plant by considering hydro and thermal power linear and non-linear limitations [26]. When compare to thermal power plants, the fuel cost of the hydro plants is inappropriate so that the objective of the HTS system is to effectively reduce the fuel cost of the thermal power generation units while ensuring efficient usage of the available hydro supply. [28].

STHTS problem is arithmetically formulated as follows

$\operatorname{Minimize}(F)=\sum_{j=1}^{N} n_{j} F_{j}\left(P T_{j}\right)$

Where $j=1,2,3, \ldots, N$ schedule interval, $F_{j}\left(P T_{j}\right)$ represents the generating cost of thermal plant in $\$ / h$ and $n_{j}$ denotes time duration in $\mathrm{j}^{\text {th }}$ interval with respect to subsequent limits:

\section{Equality limitations:}

\section{Power balance limitation}

Total power generated by allotted power plants is used to meet the load demand power with power transmission losses during the scheduled period. It is expressed as

$\left(P d_{j}+P \operatorname{Loss}_{j}\right)=\left(P H_{j}+P T_{j}\right)$

Where the transmission loss Loss $_{j}$ is given by

PLoss $=k\left(\mathrm{PH}_{j}\right)^{2}$

Water discharge rate $Q_{j}$ determines the hydroelectric power generation.

$g\left(P H_{j}\right)=Q_{j}$

Total water discharge rate $Q_{T O T}$

$\sum_{j=1}^{j \max } n_{j} Q_{j}=Q_{T O T}$

Where $Q_{\text {TоT }}=\left[V_{S}+R_{j}\right]-V_{\text {end }}$

Reservoir Volume

Volume $_{j+1}=$ Volume $_{j}+n_{j}\left(R_{j}-Q_{j}-S_{j}\right)$
Where $n_{j}$ represents the number of hours, $R_{j}$ indicates inflow rate of water, $\mathrm{Q}_{\mathrm{j}}$ shows discharge rate of water and $S_{j}$ denotes the water spillage rate at the $\mathrm{j}^{\text {th }}$ time period.

Start and end storage limit of the water reservoir

$V_{j}(0)=V_{S}$ and $V_{j}($ end $)=V_{\text {end }}$

Inequality limitations:

Water discharge rate limits

$Q_{j} \min <Q_{j}<Q_{j} \max$

The hydro generation capacity $\left(P H_{i}\right)$ and thermal generation capacity $\left(P T_{i}\right)$ are defined as

$\left(P H_{i}\right)_{\text {min }} \leq P H \leq\left(P H_{i}\right)_{\text {max }}$

$\left(P T_{j}\right)_{\text {min }} \leq P H \leq\left(P T_{j}\right)_{\text {max }}$

$\left(P H_{i}\right)_{\text {min }}$ and $\left(P T_{j}\right)_{\text {min }}$ denote the minimum hydro generation capability and thermal generation capability for the hydro unit ' $\mathrm{i}$ ' and thermal unit ' $\mathrm{j}$ '.

$\left(P H_{i}\right)_{\max }$ and $\left(P T_{j}\right)_{\max }$ denote the maximum hydro generation capability and thermal generation capability for the hydro unit ' $i$ ' and thermal unit ' $j$ ' respectively.

The storage limits of the reservoir lies in the range of

Volume $_{\text {min }}<$ Volume $_{j}<$ Volume $_{\text {max }}$

The operating parameters including the water discharge rate, highest and lowest limits of the reservoir volume and hydraulic continuity limits of the hydro units are considered. The HTS problem involves non-linear limitations and dynamic network flow limitations [1].

\section{Prohibited Operating Zones (POZs)}

Thermal and Hydro generator may have a prohibited operating zone based on the physical limitations of the components in the power plant. Vibrations will occur in the components at certain range of frequencies. When the vibration frequency is equal to the natural frequency, resonance occurs and the components may get damaged. The power outputs during the occurrence of such phenomenon are called as POZs. Hence the thermal and hydro units should not be operated in the specific POZs. For a POZ, the unit can operate only above or below the zone [29].

\section{HYBRID PSO-IBF ALGORITHM}

The control variables and parameters of the PSO and IBF algorithms are initialized. The initial population of particles is generated in a random manner. The fitness function of the PSO algorithm is formulated using the cost function. The reservoir volume output obtained from the PSO algorithm has been taken as input parameters to the IBFA. In the chemotaxis stage, the bacterium modifies its position if it discovers a domain with nutrient gradient in higher value. Then, the bacterium probably moves towards another bacterium, otherwise it tumbles in an arbitrary direction.

\section{A. PSO Algorithm}

Among all the bio-inspired algorithms, PSO provides better solution in a short central processing unit (CPU) time 
[20]. Kennedy and Eberhart [30] introduced PSO algorithm for resolving the continuous non-linear programming problems. PSO algorithm is initiated by a set of arbitrary particles. The optimal value is searched by updating the particle generation. Durin each iteration, each particle is updated using the previous (pbest) and global best (gbest) values. The particle velocity $V_{j}^{k}$ and position $x_{j}^{k}$ are updated after estimating the pbest and gbest values.

$V_{j}^{k+1}=$

$$
\begin{aligned}
& W V_{j}^{k}+c_{1} \operatorname{rand}_{1}()\left(\text { pbest }-x_{j}^{k}\right)+ \\
& c_{2} \operatorname{rand}_{2}()\left(\text { gbest }-x_{j}^{k}\right)
\end{aligned}
$$

$x_{j}^{k+1}=x_{j}^{k}+K * V_{j i}^{k+1}$

Where $V_{j}^{k}$ represents the velocity of the specific particle ' $\mathrm{j}$ ' at the iteration ' $\mathrm{k}$ ' and ' $\mathrm{W}$ ' shows the weight parameters.

$W=W_{\max }-\frac{W_{\max }-W_{\min }}{\text { iter }_{\max }} *$ iter

Where iter $_{\text {max }}$ indicates the maximum number of iterations, $c_{1}$ and $c_{2}$ denote the acceleration constants and ' $\mathrm{K}$ ' represents the constriction factor. $\operatorname{rand}_{1}()$ and $\operatorname{rand}_{2}($ ) show the uniform random numbers in the range between $[0,1]$.

\section{PSO Algorithm}

1: Initialize the particle for all populations while satisfying all the constraints.

2: Consider the previous best and global best values as initial fitness value.

3: Initialize particle velocity ' $\mathrm{V}$ ' arbitrarily between $\left[V_{\text {max }}, V_{\text {min }}\right]$

4: Update new ' $\mathrm{V}$ ' of the particle.

5: Check whether ' $\mathrm{V}$ ' exceeds the threshold limit. If it exceeds, the ' $\mathrm{V}$ ' limits are fixed.

6: Update the position of the particle ' $\mathrm{X}$ '.

7: Choose a dependent time period with unidentified particle position value.

8: Compute $Q_{i}, P H_{i}$ and $P T_{i}$ for non-dependent time periods.

9: Calculate the volume of the reservoir, $Q_{i}, P H_{i}$ and $P T_{i}$ for dependent time period.

10: Verify power generation limits to compute the fitness function.

11: Renovate the previous and global best values.

12: Repeat steps 4 to 11 until maximum iterations are attained.

\section{B. IBF Algorithm}

BFA is stimulated by the searching food activities of the Escherichia coli (E.Coli) bacteria. Passino [31] described the biotic features and mobile behaviour of the bacteria. As a heuristic optimization approach, the BFA is developed to handle non-linear problems with complicated and non-distinguishable objective functions. The solution region is searched by three major operations such as chemotaxis, reproduction, removal/dispersal events. The chemotaxis is

executed by two modes of movement such as swimming and tumbling of the bacteria. The bacterium contributes its entire life by swapping in-between these swimming and tumbling positions. The tumble $\Phi(j)$ is denoted by a unit length in arbitrary path that specifies the bacteria movement direction after a tumble. $C(i, j)$ is the constant run-length unit which denotes step size in arbitrary direction. $\theta^{i}(j, k, l) \in$ $\mathfrak{R}^{p}$ denotes $\mathrm{i}^{\text {th }}$ bacteria location at the $\mathrm{j}^{\text {th }}$ chemotactic step, the $\mathrm{k}^{\text {th }}$ reproduction step and $\mathrm{l}^{\text {th }}$ elimination/dispersal step for the bacteria population. At this point, the cost function expressed as $J(i, j, k, l)$ is referred as nutritious function. After a tumbling action the position of the $\mathrm{i}^{\text {th }}$ bacterium is denoted as

$\theta^{i}(j+1, k, l)=\theta^{i}(j, k . l)+C(i, j) \Phi(j)$

At the above location, if the cost function $J(i, j+1, k, l)$ is less than $J(i, j, k, l)$ then additional step size $C(i, j)$ is taken into account in the same direction. This swimming operation is repeated as far as the minimum cost is obtained and maximum steps $N_{s}$ are attained. Swarming operation done by the cell-to-cell signalling $J_{c c}(\theta, P)$ delivered by the group of bacteria to generate the swarm form affects the cost function. The swarming operation is defined as

$$
\begin{aligned}
J_{c c}(\theta, P(j, k, l))=\sum_{i=1}^{S} J_{c c}^{i}\left(\theta, \theta^{i}(j, k . l)\right) \\
=\sum_{i=1}^{S}\left[-d_{\text {attract }} \exp \left(-w_{\text {attract }} \sum_{m=1}^{p}\left(\theta_{m}-\theta_{m}^{i}\right)^{2}\right)\right] \\
+\sum_{i=1}^{S}\left[-h_{\text {repellant }} \exp \left(-w_{\text {repellant }} \sum_{m=1}^{p}\left(\theta_{m}\right.\right.\right. \\
\left.\left.\left.-\theta_{m}^{i}\right)^{2}\right)\right]
\end{aligned}
$$

Where $d_{\text {attract }}, w_{\text {attract }}, h_{\text {repellant }}$ and $w_{\text {repellant }}$ represents the coefficients of attractant signals and repellent signals delivered by the cell. Also $\theta_{m}^{i}$ represents the $\mathrm{m}^{\text {th }}$ component of $\mathrm{i}^{\text {th }}$ bacterium position $\theta^{i}$.

Here, $P(j, k, l)$ represents the location of every member of bacteria in the whole population, defined as

$P(j, k, l)=\left\{\theta^{i}(j, k . l) \mid i=1,2, \ldots, S\right\}$

Where ' $\mathrm{S}$ ' denotes bacteria size in population. The cost function is added with cell-to-cell signalling effect $J_{c c}(\theta, P)$.

$J(i, j, k, l)+J_{c c}(\theta, P)$

After reaching maximum chemotactic stages, the reproduction process is started. The population of the bacterium is reduced to half so that the population with minimum fitness value dies. Each bacterium in the healthy population is divided into two which has the same position.

$S_{r}=S / 2$

After the reproduction process $N_{r e}$, elimination or dispersal steps are executed for $N_{e d}$ number of executions. In this process, the bacteria can be transferred to search other regions in the search space. The fraction $p_{e d}$ determines the removal or dispersal process of each bacterium. BFA algorithm has a constant unit step length parameter that assures optimal search results 
for the optimization problems. But, it shows poor performance while applying to the complicated problems having high dimensionality. Existing BFA is improved by using the run-length factor as a main parameter to regulate the local search ability and global search capability of the BFA. This factor is adjusted to achieve a balanced investigation and exploitation search process. An effective decreasing function is applied to execute the swim walk as an alternative to the constant step. It is described as

$C(i, j)=C\left(N_{C}\right)+\left(C(1)-C\left(N_{C}\right)\right)\left(\frac{N_{C}-j}{N_{C}}\right)$

Here, chemotactic step is denoted as ' $\mathrm{j}$ ' and $N_{C}$ represents the highest number of chemotactic steps to be executed, while $C\left(N_{C}\right)$ and $C(1)$ show the predetermined factors [32].

\section{IBF Algorithm}

1: Initialize the parameters such as search space size $(p)$, bacterium population $(S)$, chemotactic steps $N_{c}$, swim length $\left(N_{S}\right)$, number of reproduction stages $\left(N_{r e}\right)$, number of elimination-dispersal actions $\left(N_{e d}\right)$, bacterium removal/ dispersal probability $\left(p_{e d}\right)$, initial run-length unit $(C(i, j))_{j=1}$, run-length unit after completing the chemotactic step $\left.C\left(N_{C}\right)\right|_{j=N_{C}}$ and initial arbitrary position of bacterium $\theta^{i}$.

2: Execute removal or dispersal step, $l=l+1$

3: Execute reproduction step, $k=k+1$

4: Execute Chemotaxis step, $j=j+1$

For $i=1,2, \ldots, S$, the chemotaxis step is executed for every bacterium as described below:

Calculate $J(i, j, k, l)$ using (15) and (17).

Let $J_{\text {last }}=J(i, j, k, l)$ thus lower cost. can be found.

Tumble: Initiate a arbitrary vector $\Delta(i) \in \mathfrak{R}^{p}$ and $\Delta_{m}(i)$, where $m=1,2, \ldots, p$ denotes an arbitrary number ranging between $[-1,1]$.

Calculate $\Phi(i)=\frac{\Delta(i)}{\sqrt{\Delta^{T}(i) \Delta(i)}}$

Relocate using the location of the bacterium using (14).

Compute $J(i, j+1, k, l)$ and apply swarming equation (15) to compute the $J_{c c}(\theta, P(j+1, k, l))$. New $J(i, j+1, k, l)$ is found out using the cell-to-cell signaling function using (17).

Swimming: let $m=0$ (counter for swim length)

While $m<N_{S}$ (no climbing down too long)

Let $m=m+1$

If $J(i, j+1, k, l)<J_{\text {last }}$, let $J_{\text {last }}=J(i, j+1, k, l)$ takes alternative step in the corresponding direction. New $J(i, j+1, k, l)$ is computed.

Move to the subsequent bacteria $(i=i+1$ if $i \neq S)$

Renovate $C(i, j)$ using a dynamic decreasing function (19)

5: If $j<N_{C}$ go to the step 4

6: Start the reproduction process
For ' $\mathrm{k}$ ' and ' $\mathrm{l}$ ', the fitness condition of every bacterium ' $\mathrm{i}$ ' is evaluated as

$J_{\text {fitness }}^{i}=\sum_{j=1}^{N_{c}+1} J(i, j, k, l)$

The fitness of the bacterium measures the amount of nutrient absorbed by the bacterium during its lifetime.

Sort the bacteria in the ascending order according to the fitness condition

The least fit bacteria will die, while the high fit bacteria divide and occupy the similar location of their parent bacteria.

7: If $k<N_{r e}$, go to step 3

8: Execute Removal or dispersal

With the probability ped, each bacterium is eliminated randomly and dispersed by maintaining bacterial population size as constant value.

9: If $l<N$, move to step 2, else, stop.

\section{SIMULATION RESULTS}

The suggested PSO-IBFA is assessed on a typical power system taken in the works proposed by Wood et al. [2, 3] and Sanjeevi Kumar et al. [29] and evaluated using the MATLAB software. The power system taken for evaluation contains one hydro power plant and one equivalent thermal power plant. The thermal power plant has the fuel cost function and it is computed as:

$f\left(P T_{j}\right)=0.00184 P T_{j}^{2}+9.2 P T_{j}+575 \$ / h$

Limit on thermal power plant

$150<P T_{j}<1500 M W$

Limit on Hydro power plant

$0<\mathrm{PH}_{j}<1100 \mathrm{MW}$

Generation of hydro power depends on water discharge and is described as:

$Q=330+4.97 P_{H}$ acre $-f t / h$ for $0 \leq P_{H} \leq 1000 M W$

$Q=5300+12\left(P_{H}-1000\right)+0.05\left(P_{H}-1000\right)^{2}$ acre $\frac{f t}{h}$ for $1000 \leq P_{H} \leq 1100 M W$

Flow limit $Q_{\min } \leq Q(i, t) \leq Q_{\max }$

$Q(i, t)$ represents the discharge rate of the water used in the hydro power plant ' $i$ ' during the period ' $t$ '.

$$
\begin{aligned}
& \text { Volume }_{\text {start }}=100000 \text { acre }-f t \\
& \text { Volume }_{\text {end }}=60000 \mathrm{acre}-\mathrm{ft}
\end{aligned}
$$

Maximum volume of the reservoir

$$
\text { Volume }_{\max }=120000 \text { acre }-f t
$$

Minimum volume of the reservoir

$$
\text { Volume }_{\text {min }}=60000 \text { acre }-f t
$$

Water inflow rate $R_{j}=2000$ acre-ft/h 
Maximum discharge rate of water: $\mathrm{Q}_{\max }=7000 \mathrm{acre}-\mathrm{ft} / \mathrm{h}$

Minimum discharge rate of water: $\mathrm{Q}_{\min }=330 \mathrm{acre}-\mathrm{ft} / \mathrm{h}$

The transmission line loss is considered as negligibly small value. Water Spillage rate of water is assumed as zero value.

Table I shows the load demand of the test case. Table II shows the POZs of the test system. Table III shows the PSO parameter values. The optimal power generation schedule and the corresponding reservoir volume and discharge rate for this system was obtained by the proposed PSO-IBF as illustrated in Table IV.

Table I - Load Demand Data for the Test System

\begin{tabular}{|c|l|c|}
\hline $\begin{array}{c}\text { Time } \\
\text { slot }\end{array}$ & \multicolumn{1}{|c|}{ Interval duration } & $\begin{array}{c}\text { Power Demand } \\
\text { (MW) }\end{array}$ \\
\hline 1 & 0-12 hours (First day) & 1200 \\
\hline 2 & 12-24 hours (First day) & 1500 \\
\hline 3 & $0-12$ hours (Second day) & 1100 \\
\hline 4 & 12-24 hours (Second day) & 1800 \\
\hline 5 & 0-12 hours (Third day) & 950 \\
\hline 6 & 12-24 hours (Third day) & 1300 \\
\hline
\end{tabular}

Table II - POZ of the test system

\begin{tabular}{|c|c|c|}
\hline Zone I & Zone II & Zone III \\
\hline $870-890$ & $790-810$ & $750-755$ \\
\hline
\end{tabular}

Table III - PSO parameters values

\begin{tabular}{|l|c|}
\hline \multicolumn{1}{|c|}{ Parameters } & Values \\
\hline Variable quantity & 6 \\
\hline Population size & 100 \\
\hline Highest weight of inertia & 0.9 \\
\hline Lowest weight of inertia & 0.4 \\
\hline Acceleration factor c1 & 2.5 \\
\hline Acceleration factor c2 & 2.5 \\
\hline
\end{tabular}

Table IV - Performance evaluation results of PSO algorithm

\begin{tabular}{|c|c|c|c|c|c|}
\hline $\begin{array}{l}\text { Int } \\
\text { erv } \\
\text { al }\end{array}$ & $\begin{array}{l}\text { Hydro } \\
\text { Power } \\
\text { (MW) }\end{array}$ & $\begin{array}{c}\text { Thermal } \\
\text { Power (MW) }\end{array}$ & $\begin{array}{l}\text { Volum } \\
\text { e } \\
\text { (acre-f } \\
\text { t) }\end{array}$ & $\begin{array}{c}\text { Water } \\
\text { Discharge } \\
\text { Rate } \\
\text { (acre-ft/h) }\end{array}$ & $\begin{array}{c}\text { Fuel } \\
\text { Cost (\$) }\end{array}$ \\
\hline 1 & 703.6887 & 496.3113 & 97942 & 3827.3328 & \multirow{6}{*}{$\begin{array}{l}\infty \\
\infty \\
\infty \\
\infty \\
\infty \\
\sigma\end{array}$} \\
\hline 2 & 267.0802 & 1232.9197 & 114803 & 1657.3888 & \\
\hline 3 & 551.8106 & 548.1893 & 67619 & 3072.4990 & \\
\hline 4 & 682.3970 & 1117.6029 & 114348 & 3721.5133 & \\
\hline 5 & 521.5183 & 428.4816 & 108884 & 2921.9461 & \\
\hline 6 & 397.6580 & 902.3419 & 60000 & 2306.3605 & \\
\hline
\end{tabular}

The power generation stops when the reservoir volume reaches 60000 acre- $\mathrm{ft}$. The Fuel Cost $(\$)$ is 658381.8 . Figure.1 shows the PSO convergence characteristics. The PSO algorithm converges to the optimum value at the minimum number of iterations. Thus, the proposed work yields minimum cost value than the existing work proposed by Samudi et al. [33] by considering the POZs for STHTS. Table $\mathrm{V}$ depicts the parameter values of the IBFA. The minimum cost value obtained finally from the IBF algorithm is 639846.4\$. Table VI shows the power plant generation schedule and accompanying reservoir volume, discharge rate of water of the power system.
Figure.2 shows the IBFA convergence characteristic. The IBF algorithm converges quickly at the minimum cost value than the existing algorithms. The proposed PSO-IBF algorithm can yield global optimal solution and require minimum computation time.

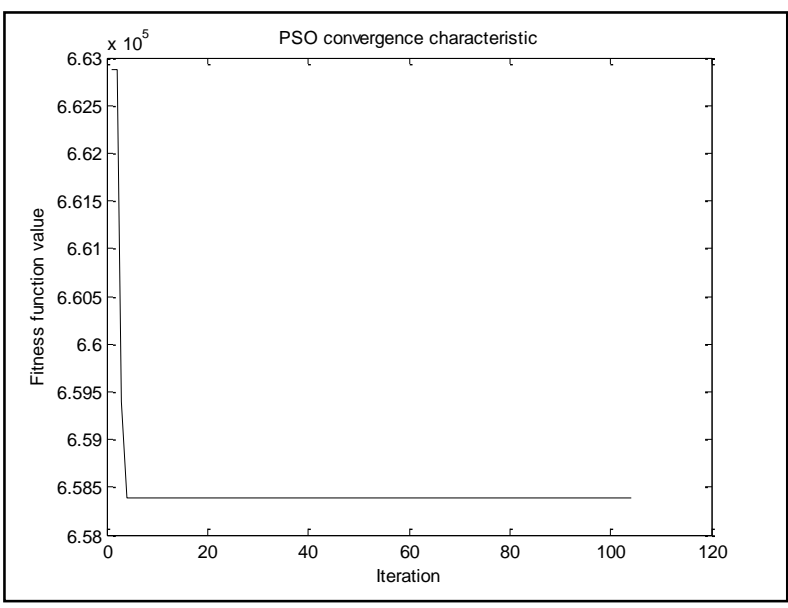

Figure 1. PSO convergence rate

Table V - IBFA parameters values

\begin{tabular}{|l|c|}
\hline \multicolumn{1}{|c|}{ Parameters } & Values \\
\hline Search space size & 6 \\
\hline Bacterial count & 50 \\
\hline Amount of chemotactic steps & 50 \\
\hline Swim length & 4 \\
\hline Reproduction step number & 4 \\
\hline Removal-dispersal action number & 6 \\
\hline Bacteria reproduction rate per generation & $S_{r}=s / 2$ \\
\hline Removal/dispersal probability of each bacteria & 0.25 \\
\hline
\end{tabular}

Table VI - Performance evaluation results of IBF algorithm

\begin{tabular}{|c|c|c|c|c|c|}
\hline Interval & $\begin{array}{l}\text { Hydro } \\
\text { Power } \\
\text { (MW) }\end{array}$ & $\begin{array}{c}\text { Thermal } \\
\text { Power } \\
\text { (MW) }\end{array}$ & $\begin{array}{l}\text { Volume } \\
\text { (acre-ft) }\end{array}$ & $\begin{array}{c}\text { Water } \\
\text { Discharge } \\
\text { Rate (acre- } \\
\text { ft/h) }\end{array}$ & $\begin{array}{l}\text { Fuel Cost } \\
\text { (\$) }\end{array}$ \\
\hline 1 & 768.8603 & 431.1396 & 79263.7099 & 4151.2360 & \multirow{6}{*}{639846.4} \\
\hline 2 & 467.0802 & 1032.9197 & 72470.3355 & 2651.3888 & \\
\hline 3 & 461.8108 & 638.1891 & 70267.6168 & 2625.2000 & \\
\hline 4 & 582.3971 & 1217.6028 & 81807.0275 & 3224.5138 & \\
\hline 5 & 350.5393 & 599.4606 & 85617.587 & 2072.1805 & \\
\hline 6 & 597.6581 & 702.3418 & 59999.8059 & 3300.3611 & \\
\hline
\end{tabular}

Table VII provides the comparison results for the test system using various optimization algorithms. From the comparison of results, it is very clear that the proposed method is able to give global optimal solution and computation time of PSO-IBFA is very low compared with existing methods. Thus the potential of finding optimal solution with affordable time to the short term hydrothermal scheduling problem by proposed PSO-IBF algorithm is proved. Since the proposed method applies a dynamic decreasing function for updating the solution vector, the convergence characteristics of the algorithm are much improved. 


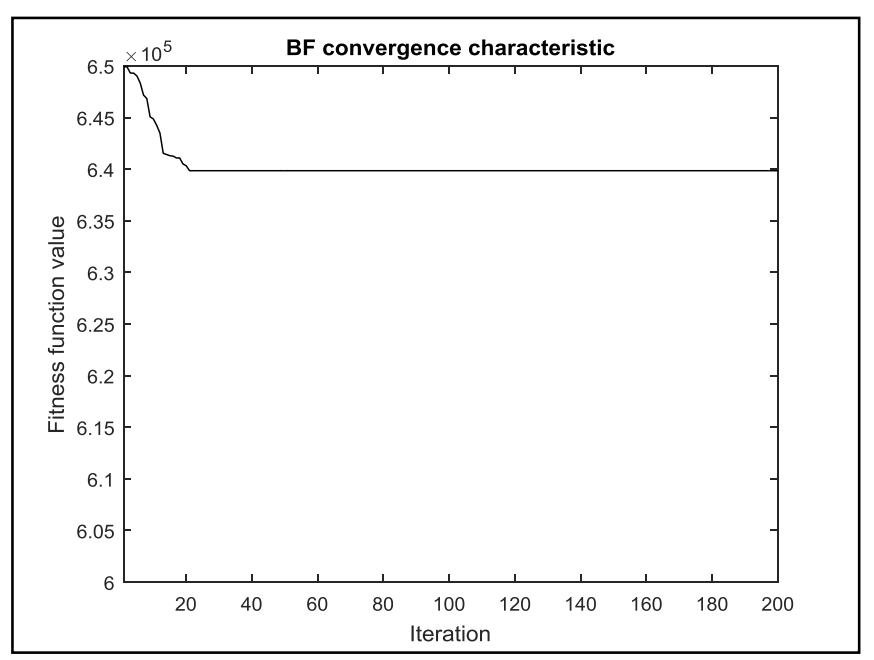

Figure.2 IBFA convergence characteristic

Table VII - Comparison results for the test system using various optimization algorithms

\begin{tabular}{|c|l|c|c|}
\hline S.No & \multicolumn{1}{|c|}{ Authors } & Method & Cost (\$) \\
\hline 1 & Wood. A. J & GS [3] & 709877.38 \\
\hline 2 & Wong. K. P. et.al. & SA [10] & 709870.46 \\
\hline 3 & Davis. L. & GA [34] & 709863.56 \\
\hline 4 & Sinha et. al. & IFEP [18] & 709862.05 \\
\hline 5 & Nidul Sinha et.al & PSO [20] & 709862.048 \\
\hline 6 & Nallasivan et.al. & Hybrid EP [19] & 703180.26 \\
\hline 7 & Samudi et.al & PSO [33] & 696002.3 \\
\hline 8 & Farhat et.al & IBFA [32] & 709837.926 \\
\hline 9 & Sanjeev kumar et.al & GA-PSO-TS [29] & 709862.0 \\
\hline 10 & Balachander et al. & FPA [28] & 693427.16 \\
\hline 11 & Balachander et al. & Proposed PSO-IBFA & 639846.4 \\
\hline
\end{tabular}

\section{CONCLUSION}

This research paper has proposed a combined PSO-IBF algorithm for solving the STHTS problem. Since the HTS problem is highly non-linear, this combined PSO-IBF algorithm outperforms the existing meta-heuristic algorithms with respect to fuel cost function and convergence rate. By selecting reservoir water volume as a position of the particle, the PSO algorithm can avoid the local minima. The PSO algorithm yields better convergence to the global optimum solution than other evolutionary methods due to the particle position and velocity update steps, despite of the discontinuities of the cost function. The PSO algorithm is highly robust in controlling the parameters and computationally efficient. It is highly skillful to keep diversity of the swarm as all the particles utilize the information associated with the best particle for self-improvement. The IBFA provides an improved investigation approach due to the chemotaxis approach. It helps to quickly leap from the nearby minimal value and decreases the inconsistent of the PSO algorithm in a wide-scale system along with numerous limitations, as it is driven by more vectors. From the simulation results, it is clearly concluded that the combined PSO-IBF algorithm can give the global optimal solution at a lesser computation time.

\section{REFERENCES}

1. O. Hoseynpour, B. Mohammadi-Ivatloo, M. Nazari-Heris, and S. Asadi, "Application of dynamic non-linear programming technique to non-convex short-term hydrothermal scheduling problem," Energies, vol. 10, p. 1440, 2017.
2. A. J. Wood, B. F. Wollenberg, and P. Generation, "Operation and Control ", $\square$ John Wiley \& Sons," New York, 1984.

3. A. J. Wood and B. F. Wollenberg, Power generation, operation, and control: John Wiley \& Sons, 2012.

4. S. Wang, S. Shahidehpour, D. S. Kirschen, S. Mokhtari, and G. Irisarri, "Short-term generation scheduling with transmission and environmental constraints using an augmented Lagrangian relaxation," IEEE Transactions on Power Systems, vol. 10, pp. 1294-1301, 1995.

5. V. N. Dieu and W. Ongsakul, "Improved merit order and augmented Lagrange Hopfield network for short term hydrothermal scheduling," Energy Conversion and Management, vol. 50, pp. 3015-3023, 2009.

6. R. Ferrero, J. Rivera, and S. Shahidehpour, "A dynamic programming two-stage algorithm for long-term hydrothermal scheduling of multireservoir systems," IEEE Transactions on Power Systems, vol 13, pp. 1534-1540, 1998

7. L. Martinez and S. Soares, "Primal and dual stochastic dynamic programming in long term hydrothermal scheduling," in Power Systems Conference and Exposition, 2004. IEEE PES, 2004, pp. 1283-1288.

8. Y. Jin-Shyr and C. Nanming, "Short term hydrothermal coordination using multi-pass dynamic programming," IEEE Transactions on Power Systems, vol. 4, pp. 1050-1056, 1989.

9. K. Wong and Y. Wong, "Short-term hydrothermal scheduling part. I. Simulated annealing approach," IEE Proceedings-Generation, Transmission and Distribution, vol. 141, pp. 497-501, 1994.

10. K. Wong and Y. Wong, "Short-term hydrothermal scheduling. II. Parallel simulated annealing approach," IEE Proceedings-Generation, Transmission and Distribution, vol. 141, pp. 502-506, 1994.

11. S. Y. W. Wong, "Hybrid simulated annealing/genetic algorithm approach to short-term hydro-thermal scheduling with multiple thermal plants," International journal of electrical power \& energy systems, vol. 23, pp. 565-575, 2001.

12. Y.-G. Wu, C.-Y. Ho, and D.-Y. Wang, "A diploid genetic approach to short-term scheduling of hydro-thermal system," IEEE Transactions on Power Systems, vol. 15, pp. 1268-1274, 2000.

13. E. Gil, J. Bustos, and H. Rudnick, "Short-term hydrothermal generation scheduling model using a genetic algorithm," IEEE Transactions on power systems, vol. 18, pp. 1256-1264, 2003

14. C. E. Zoumas, A. G. Bakirtzis, J. B. Theocharis, and V. Petridis, "A genetic algorithm solution approach to the hydrothermal coordination problem," IEEE Transactions on Power Systems, vol. 19, pp. 1356-1364, 2004.

15. R. Naresh and J. Sharma, "Short term hydro scheduling using two-phase neural network," International journal of electrical power \& energy systems, vol. 24, pp. 583-590, 2002.

16. P.-C. Yang, H.-T. Yang, and C.-L. Huang, "Scheduling short-term hydrothermal generation using evolutionary programming techniques," IEE Proceedings-Generation, Transmission and Distribution, vol. 143, pp. 371-376, 1996.

17. M. Basu, "An interactive fuzzy satisfying method based on evolutionary programming technique for multiobjective short-term hydrothermal scheduling," Electric Power Systems Research, vol. 69 pp. 277-285, 2004.

18. N. Sinha, R. Chakrabarti, and P. Chattopadhyay, "Fast evolutionary programming techniques for short-term hydrothermal scheduling," Electric Power System Research, vol. 66, pp. 97-103, 2003.

19. C. Nallasivan, D. Suman, J. Henry, and S. Ravichandran, "A novel approach for short-term hydrothermal scheduling using hybrid technique," IEEE Power India Conference, April 2006.

20. N. Sinha and L.-L. Lai, "Meta heuristic search algorithms for short-term hydrothermal scheduling," in Machine Learning and Cybernetics, 2006 International Conference on, 2006, pp. 4050-4056.

21. B. Yu, X. Yuan, and J. Wang, "Short-term hydro-thermal scheduling using particle swarm optimization method," Energy Conversion and Management, vol. 48, pp. 1902-1908, 2007.

22. K. K. Mandal, M. Basu, and N. Chakraborty, "Particle swarm optimization technique based short-term hydrothermal scheduling," Applied Soft Computing, vol. 8, pp. 1392-1399, 2008.

23. C. Sun and S. Lu, "Short-term combined economic emission hydrothermal scheduling using improved quantum-behaved particle swarm optimization," Expert Systems with Applications, vol. 37, pp. 4232-4241, 2010.

24. J. Zhang, J. Wang, and C. Yue, "Small population-based particle swarm optimization for short-term hydrothermal scheduling," IEEE Transactions on Power Systems, vol. 27, pp. 142-152, 2012.

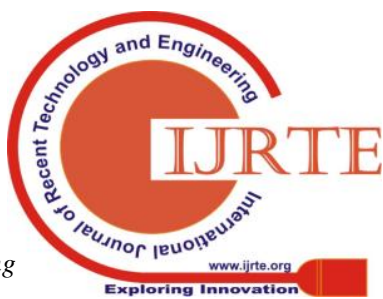


25. Y. Wang, J. Zhou, C. Zhou, Y. Wang, H. Qin, and Y. Lu, "An improved self-adaptive PSO technique for short-term hydrothermal scheduling," Expert Systems with Applications, vol. 39, pp. 2288-2295, 2012.

26. P. Ramesh, "Short term hydrothermal scheduling in power system using improved particle swarm optimization," Int $\mathbf{J}$ Adv Engg Tech/Vol. VII/Issue I/Jan.-March, vol. 602, p. 606, 2016.

27. A. Y. Saber, "Economic dispatch using particle swarm optimization with bacterial foraging effect," International Journal of Electrical Power \& Energy Systems, vol. 34, pp. 38-46, 2012.

28. T. Balachander, P. A. Jeyanthy, and D. Devaraj, "Short term hydro thermal scheduling using flower pollination algorithm," in Intelligent Techniques in Control, Optimization and Signal Processing (INCOS), 2017 IEEE International Conference, 2017, pp. 1-5.

29. J. Sanjeevikumar and M. Sudhakaran, "Application of integrated GA-PSO-TS algorithm for solving hydro thermal scheduling problem with prohibited operating zones," International Journal of Applied Engineering Research, vol. 11, pp. 3842-3847, 2016.

30. J. Kennedy, "Particle swarm optimization," in Encyclopedia of machine learning, ed: Springer, 2011, pp. 760-766.

31. K. M. Passino, "Biomimicry of bacterial foraging for distributed optimization and control," IEEE control systems, vol. 22, pp. 52-67, 2002.

32. [32] I. Farhat and M. El-Hawary, "Short-term hydro-thermal scheduling using an improved bacterial foraging algorithm," in Electrical Power \& Energy Conference (EPEC), 2009 IEEE, 2009, pp. $1-5$.

33. [33] C. Samudi, G. P. Das, P. C. Ojha, T. Sreeni, and S. Cherian, "Hydro thermal scheduling using particle swarm optimization," in Transmission and Distribution Conference and Exposition, 2008. T\&D. IEEE/PES, 2008, pp. 1-5.

34. L. Davis, "Handbook of genetic algorithms," 1991. 